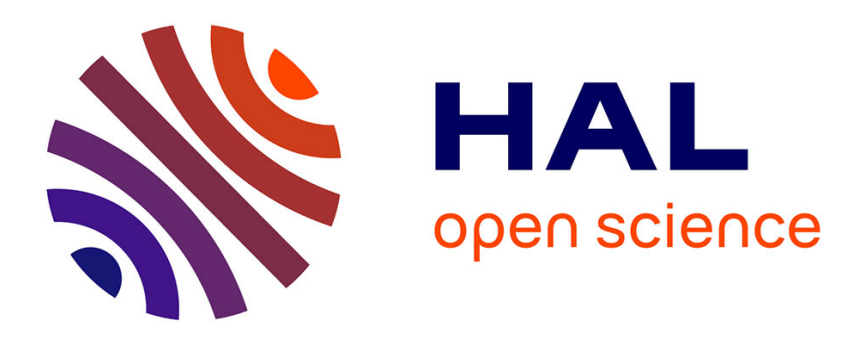

\title{
Toward a Group Facilitation Technique for Project Teams
}

\author{
Erich H. Witte
}

\section{To cite this version:}

Erich H. Witte. Toward a Group Facilitation Technique for Project Teams. Group Processes and Intergroup Relations, 2007, 10 (3), pp.299-309. 10.1177/1368430207078694 . hal-00571654

\section{HAL Id: hal-00571654 \\ https://hal.science/hal-00571654}

Submitted on 1 Mar 2011

HAL is a multi-disciplinary open access archive for the deposit and dissemination of scientific research documents, whether they are published or not. The documents may come from teaching and research institutions in France or abroad, or from public or private research centers.
L'archive ouverte pluridisciplinaire HAL, est destinée au dépôt et à la diffusion de documents scientifiques de niveau recherche, publiés ou non, émanant des établissements d'enseignement et de recherche français ou étrangers, des laboratoires publics ou privés. 


\title{
Toward a Group Facilitation Technique for Project Teams
}

\author{
Erich H. Witte \\ University of Hamburg, Germany
}

This article presents the development of a group facilitation technique (PROMOD Procedural Moderation). The author points toward the importance of integrating theoretical assumptions, theory testing and basic empirical research with practical application. The results are based on the observation of various three-member task groups faced with a complex nonheureka problem. These comprise naturally interacting groups, simple arithmetic assembled groups of individuals without any interaction (synthetic groups), and groups in which a group technique of reduced interaction which focuses on individual contribution through facilitated knowledge elicitation is applied.The task involves decisions on what to do after a plane crash and ranking objects with regard to their importance for survival in an alarming situation (Lafferty \& Pond, 1974). The group decision quality is determined by relating to conclusions reached by an independent expert. Results indicate that the observed teams performed best when the PROMOD procedure was applied.

KEYWORDS facilitation techniques for groups, group decision making, group performance, project teams, theory construction

For about the last 50 years, scientists have been aware of the difficulties which arise when groups make decisions (Davis, 1996; Hinsz, Tindale, \& Vollrath, 1997; Kerr \& Tindale, 2004). The popular assumption that groups nearly always show greater aptitude for problem solving tasks than individuals has been refuted by a vast amount of intensive research. Only very few exceptions to those results have been published (Laughlin, Zander, Knievel, \& Tan, 2003).

The time has come to shift the emphasis of social psychology research to the question of how to enable groups to achieve greater quality in problem solving. In addition to pointing out the effects of process losses, research should focus on the development of group facilitation techniques which produce process gains and synergetic effects when people make decisions in committees or project teams (Messé, Hertel, Kerr, Lount, \& Park, 2002).

Today, the use of project teams comprised of experts in various fields of knowledge has been established on a world-wide scale. The cooperation of such experts aims at finding the optimal solutions possible for complex problems in an increasingly complex world. This procedure

\section{$\overline{\text { Author's note }}$}

Address correspondence to Erich H. Witte,

University of Hamburg, Department of

Psychology, Von-Melle-Park 5, D-20146

Hamburg, Germany

[e-mail: witte_e_h@uni-hamburg.de] 
is closely connected to the idea that teams are able to successfully integrate various pertinent viewpoints, thereby improving the quality of solutions and decisions. Instead, process losses in groups cause considerable productivity losses concerning all areas of society. Supposing we were able to support project teams in improving the quality of their decisions and solutions when dealing with complex problems by developing efficient group techniques, then small group research could again occupy a central position in social psychology.

Although primarily a field of applied research, it seems to be important to simultaneously develop theoretical baseline-models which serve as supporting stimulation for applied approaches in this field. These models could provide a basis for the development of techniques, a framework for the integration of various data, as well as an instrument to disclose and explain the inconsistencies occurring in results. Mutual inspiration is needed. Up till now there has been a lack of theoretical background which could serve as a guide for empirical procedures (Katzenstein, 1996). The well-known brainstorming technique was introduced without any theoretical baseline and no fundamental research. Endeavors to find theoretical explanations as to why brainstorming does not lead to the expected effects began long after its implementation (see Nijstad, Stroebe, \& Lodewijkx, 2003; Stroebe, Diehl, \& Abakoumkin, 1992).

\section{Starting points}

The following facts are intended to provide a basis for further consideration:

a. Increasing complexity of all societal systems requires the cooperation of various experts to solve highly complex problems and to take decisions for future societal developments.

b. In general, team members believe in the high quality of group decisions per se.

c. In contrast, research on small group performance shows process losses which lower the quality of group decisions and increase the probability of inadequate solutions.

d. Group techniques like
- Group facilitation techniques (i.e., the Delphi method);

- Discourse techniques (i.e., brainstorming); and

- Group development techniques (i.e., encounter groups).

do not lead to sophisticated group decisions (Dalkey \& Helmer, 1963; Innami, 1994; Katzenstein, 1996; Moore, 1987; Osborn, 1957; Rogelberg, Barnes-Farrell, \& Lowe, 1992; Rogers, 1970; Schweiger, Sandberg, \& Ragan, 1986).

\section{Group performance: Facilitative and inhibitory conditions}

A substantial criterion for group techniques is their capacity to enforce facilitative elements of group processes and to reduce inhibitory processes. Therefore the analysis of facilitative and inhibitory conditions for group performances is fundamental. Several of those conditions are already well known. On the one hand we can distinguish effects on individual and group levels and, on the other hand, cognitive, emotional and behavioral processes on both levels.

Attempts to improve group performance by structuring the discussion process have not proved sufficiently successful, as group dynamic phenomena still have a negative influence on group productivity ('majority wins'-the correct solution needs a majority to be accepted; social loafing-reducing the individual effort in group conditions; shared view effect also known as common knowledge effect-discussing the shared information between group members and ignoring the unique information of each member when solving a hidden profile; choice shift-becoming more extreme after group discussion; and group think-making poor decisions following a discussion among highly recommended experts (Kerr \& Tindale, 2004; Witte \& Davis, 1996a, 1996b)). Thus, group interaction has to be reduced to a minimum, individual positions have to be strengthened and individual motivation has to be supported.

Widespread assumptions that 'emotional' group cohesion perse leads to better group decisions have been disproved (Mullen \& Copper, 1994). 
Against the background of the abovementioned phenomena of group dynamic influences on group decision quality (Kerr \& Tindale, 2004), the following postulates are considered fundamental to improving group performance results:

1. The higher the quality of individual input regarding the subject matter at the beginning of the group interaction, the higher the quality of the group performance (Grofman, 1978; Lorge \& Solomon, 1955; Sorkin, Hays, \& West, 2001).

2. The more individual inputs are independent of one another at the beginning of the group interaction, the higher the quality of the group performance (Sorkin et al., 2001).

3 . The more the group increases individual independent inputs, the higher the quality of the group performance (Hinsz et al., 1997).

4. The more comprehensible the individual input is for each group member, the higher the quality of the group performance (Libby, Trotman, \& Zimmer, 1987).

5. The more high quality individual input influences the final group decision, the higher the quality of the group performance (Littlepage, Schmidt, Whisler, \& Frost, 1995).

Normative influences on group performance processes can manipulate and distort the informational integration of individual input (Hinsz et al., 1997) and should therefore be reduced to a minimum. The general maxim for a group facilitation technique for project teams has to be read as follows:

- maximize the informational influence on the group performance process;

- minimize the normative influence on the group performance process; and

- optimize the influence of individual input on the final group decision (see Formula 3).

This general maxim is also related to Steiner's classical ideas on group productivity (1972) in which he differentiates between three classes of variables: task demands, resources and process.
The potential productivity of the group in the sense of Steiner depends on the task demands, the individual resources of the members and the 'utilization pattern' (p. 7) by which these resources are combined into a group product. The general task I have in mind is a complex problem solving task which demands a combination of information. Thus, in general, the maxim is the description of how to organize the process under a condition in which the input of restricted individual resources is optimized to the highest possible degree.

Project teams often comprise experts from various subject areas. Each of those experts has specialized knowledge which other group members do not have (unshared knowledge). In addition, the group's resource includes knowledge which is at the disposal of all group members (shared knowledge). Conformity processes, as part of normative pressure in groups, result in primarily shared knowledge entering into a consensual group decision, and specialized knowledge remaining unnoticed (the shared view effect). Thus, the unique resources of single group members have to be explicitly extracted and communicated to the group (Hoffman, Shadbolt, Burton, \& Klein, 1995). The importance of each contribution of knowledge with respect to the group decision should then be evaluated by the group. Therefore all comments, arguments and individual positions must be presented to the group in a clear and comprehensible way, as they cannot be taken for granted per se, especially as specialists in a certain field often tend to underestimate the complicated nature of their expertise. To sum up: the quality of group performance regarding non-heureka tasks considerably depends on the addition of shared and unshared knowledge in groups and its evaluation (weight). This postulate was formalized by Shiflet (1979).

\section{General model of group productivity}

$\mathrm{P}=\sum_{i=1}^{n} \mathrm{X}_{\mathrm{i}} \cdot \mathrm{C}_{\mathrm{i}}+\sum_{i=1}^{n} \mathrm{Y}_{\mathrm{i}} \cdot \mathrm{D}$

$\mathrm{P}$ : group performance

$\mathrm{X}_{\mathrm{i}}$ : weight reflecting the importance of unshared knowledge contributions 
$\mathrm{C}_{\mathrm{i}}$ : unshared knowledge contributions of individual $\mathrm{i}$

$\mathrm{Y}_{\mathrm{i}}$ : weight reflecting the importance of shared knowledge contributions

D: shared knowledge contribution

The quality of group performance not only depends on the cross-section of shared and unshared knowledge but also on the extent of relating the knowledge to the task; in other words, putting the knowledge to use in the task-handling (Greitemeyer \& Schulz-Hardt, 2003). This understanding leads to further postulates:

6. The more the individual knowledge of all group members is linked to the requirements of task performance, the higher the potential of the group performance.

7. The more the items of individual knowledge of group members are independent of each other, the more the potential performance of the group is reached.

These postulates can be formalized as follows:

$$
\begin{aligned}
\mathrm{PP} & =\left(\bigcup_{i=1}^{n} C_{i}\right) \cap \mathrm{T} \\
& =\left(\mathrm{C}_{\mathrm{i}} \cap \mathrm{T}\right) \mu\left(\mathrm{C}_{\mathrm{i}+1} \cap \mathrm{T}\right) \mu\left(\mathrm{C}_{\mathrm{i}+2} \cap \mathrm{T}\right) \ldots
\end{aligned}
$$

PP: potential performance of the group

$\mathrm{UC}_{\mathrm{i}}$ : the logical union of all members' independent resources

$\mathrm{C}_{\mathrm{i}}$ : unique resources of each group member

$\cap$ : logical cross-section

T: all (nearly infinite) elements of the task

$\mu$ : logical union of single elements

In some cases the sum knowledge of a group is not sufficient to solve a problem in a high quality manner. If the selection of group members for a certain task is unsatisfactory, this, of course, cannot be compensated by any group facilitation technique.

The combination of the two arithmetic mean (a.m.) formulas shows that $\mathrm{X}_{\mathrm{i}}$ (weight reflecting the importance of unshared knowledge contributions) should be a function of $\left(\mathrm{C}_{\mathrm{i}} \cap \mathrm{T}\right)$, which is of vital importance for reaching a group performance $(\mathrm{P})$ which comes near to the potential performance $(\mathrm{PP})$ of a group:

$$
X_{i}=f\left(C_{i} \cap T\right)
$$

Shared knowledge contribution $\left(\mathrm{Y}_{\mathrm{i}}\right)$ has to be seen as a function to initiate, control and steer a normatively organized group dynamic process, as group members like to discuss shared knowledge, which increases the willingness to tackle the task. Nevertheless, it has to be emphasized that such normative processes distract from important unshared knowledge exchange and as a consequence hinder an optimal group performance (PP). The maxim of an efficient group facilitation technique is to reduce the shared knowledge contribution to a minimum $\left(\mathrm{Y}_{\mathrm{i}} \rightarrow 0\right)$ and to maximize informational influence of unshared knowledge.

Combining the postulates from basic research to find a group facilitation technique as a complex application leads to the following postulate:

8. The more a group facilitation technique enables the realization of the above quoted conditions in a group setting (postulates 1 to 5), the higher the quality of the group performance and the more the performance comes closer to the potential performance (PP).

Without any group facilitation technique free interacting groups are seldom able to follow the conditions necessary for efficient group performance (Davis, 1992; Kerr \& Tindale, 2004).

\section{The development of a group facilitation technique for project teams}

The above-mentioned postulates require adequate pragmatic implementation when developing a group facilitation technique for project teams. The group facilitation technique PROMOD (Procedural Moderation) has been designed in accordance with the considerations stated below (Lecher \& Witte, 2002; Witte \& Sack, 1999).

Derivations from Postulate 1 In order to increase the individual member's quality of 
performance, the specialized knowledge has to be elicited by a structured and individualoriented technique which also aims to prevent social loafing and free-riding effects (Hoffman et al., 1995; Scheele \& Groeben, 1988).

Derivations from Postulate 2 In order to support subjective points of view independent of other subjects' opinions and under no influence of conformity pressure, group members first develop their own arguments and problem solving strategies without any personal contact with other group members. A facilitator for each group member gives social-emotional feedback and motivational support and provides a common structure for eliciting the knowledge of each expert.

Derivations from Postulate 3 In order to consider all individual information, this should be exchanged among the group members in a condition which excludes any normative influence. Consequently all information will be passed on anonymously.

Derivations from Postulate 4 In order to achieve a high general comprehension of each specialized analysis of the topic, the facilitator must be able to pass on thoughts and opinions both lucidly and logically without, of course, interfering in terms of content.

Derivations from Postulate 5 In order to integrate all high quality information into the final group decision, the facilitator tries to minimize any irrelevant influences, e.g., extraversion of the author, talkativeness or other social characteristics (Littlepage et al., 1995). The anonymous procedure of exchanging information facilitates an objective evaluation of this information. Furthermore, the integration rule for the final group product should be defined from outside by consensus or majority vote.

General assumptions A group facilitation technique which adheres to the above-mentioned derivations from the postulates should:

- maximize the informational influence on the group performance process;
- minimize the normative influence on the group performance process; and

- optimize the influence of individual input on the final group decision, in keeping with the three prerequisites of our general maxim for an efficient group facilitation technique.

\section{The group facilitation technique PROMOD}

The group facilitation technique PROMOD (Procedural Moderation) has been developed on the basis of thorough analysis of group interaction processes and their significance for the cognitive performance productivity of a team; it aims to prevent process losses in project teams and generate process gains and synergy effects. PROMOD is a group facilitation technique for project teams, i.e., for groups which work on a special task for a limited period of time.

\section{Individual production procedure}

All group members work physically separated from each other guided by a facilitator, who rigidly structures the individual performance process according to a general scheme comprising several steps on how to tackle the task. This is a fundamental characteristic of the PROMOD technique. Another characteristic of PROMOD is that each group member writes down his or her own argument pro or con various decision alternatives, thereby eliminating oral communication.

\section{Production process}

First the status quo is analyzed in detail. Then various alternative targets are formulated in order to improve the status quo and in order to tackle existing problems. Arguments pro and con different targets clarify which decision has to be taken. Then reasons are given for suggested measures and steps on how to arrive at the targets. The written documents serve as external memories during the decision making process and therefore simplify a complex cognitive procedure.

\section{Means of communication}

At a fixed time the facilitators exchange all individual drafts among all group members. The 
group members remain anonymous throughout. Thus a social assessment of the information based on the group members' hierarchical position, eloquence, sympathy or antipathy, etc. is eliminated.

All group members give a commentary on the other drafts with a view to the quality of the argument. After the written comments and the propositions of the other members are noted individual final drafts are worked out, which will then be integrated into a common decision. This integration is the result of a consensus, a majority vote if there are qualitative decisions or as a last resort a mathematically oriented aggregation strategy, like the mean, median or mode of the individual decisions after the exchange process. (The group members are told this at the beginning of the process.)

\section{Task demands}

Different tasks require different structures, i.e. the written scheme has to be adapted to the type of task being focussed on (decision making, problem solving, brainstorming, rule induction, technology evaluation, jury decision making, conflict resolution, etc.). A logical structuring of the decision process is mostly missing in real group discussions (Hackman \& Morris, 1975).

\section{The facilitators' duties}

The facilitators' job consists in leading the group members through the task structure and supporting them by asking specific questions, such as 'Are these all measures you can imagine?' or 'Please explain more precisely the reason for your decision'. At no time do the facilitators intervene with regard to the content of arguments. The presence of a facilitator should furthermore compensate for the missing socio-emotional aspect of face-to-face interaction and provide social support.

\section{About The Desert Survival Problem}

\section{Method $^{1}$}

Participants and design The subjects of the group setting comprised 270 people: students of the University of Hamburg belonging to various faculties: Social Sciences, Economics and Law; students of the 'Bundeswehr' (German armed forces); policemen in further education; and adults attending various schools of further education. The group composition was identical with regard to subjects of different courses of study. The average age of the sample was 24. The subjects received a remuneration of 10 Euros.

The communication modality varied depending on whether groups of three members worked under PROMOD instructions or under noPROMOD instructions (the control group).

Furthermore, 'synthetic groups' were built: the results of three subjects working individually on solving the tasks were combined at random. The arithmetic mean of the individual results served as the group performance result. The communication modality varied depending on whether the subjects working individually had no guidance by the PROMOD technique or whether they worked under PROMOD conditions as described above $(2 \times 2$ experimental design) (Table 1$)$.

Experimental task To test the effectiveness of the PROMOD technique we conducted the following experiment introducing a ranking task (Lafferty \& Pond, 1974). As the efficiency of PROMOD, among other effects, essentially results from a stringent structure for eliciting expert knowledge, it was our intention to verify if an additional increase of group decision quality can still be achieved by applying the PROMOD group facilitation technique when working with this highly structured task.

The Desert Survival Problem is a well investigated non-heureka problem solving task. The correctness or incorrectness of a decision cannot be clearly identified. Several given objects have to be ranked with regard to their usefulness in order to survive in a precarious situation. The quality of the results is expressed by the deviation from an expert conclusion about the rank order.

Measures and procedure The main group performance measure is expressed in the absolute difference between the group ranking and an expert rank order. The maximal amount of 
Table 1. Experimental design About The Desert Survival Problem

\begin{tabular}{|c|c|c|}
\hline & $\begin{array}{l}\text { Real interacting groups: } \\
\text { Face-to-face or written communication }\end{array}$ & Nominal groups \\
\hline \multicolumn{3}{|l|}{ No PROMOD technique applied } \\
\hline Means of communication & Face-to-face interaction & No interaction, individual work \\
\hline Information exchange & Oral discussion & No information exchange \\
\hline Determination of result & $\begin{array}{l}\text { Reaching a consensus by oral discussion, } \\
\text { majority vote or as a last resort by } \\
\text { statistical aggregation of individual } \\
\text { decisions after discussion }\end{array}$ & $\begin{array}{l}\text { Statistical means of individual } \\
\text { results }\end{array}$ \\
\hline Number of groups & 27 groups & 18 groups \\
\hline \multicolumn{3}{|l|}{ PROMOD technique applied } \\
\hline Means of communication & In writing & No interaction, individual work \\
\hline $\begin{array}{l}\text { Information exchange based } \\
\text { on a problem structure }\end{array}$ & Anonymous, writing & No exchange, writing \\
\hline Determination of result & $\begin{array}{l}\text { Reaching a consensus, majority vote } \\
\text { by written information exchange or } \\
\text { as a last resort by statistical aggregation } \\
\text { of individual decisions after exchange }\end{array}$ & $\begin{array}{l}\text { Statistical means of individual } \\
\text { results }\end{array}$ \\
\hline Number of groups & 27 groups & 27 groups \\
\hline
\end{tabular}

deviation points (errors) is 112. In order to get a 'synthetic' group, the arithmetic mean of the individual points is used as the group performance measures.

Group performance $=$

$$
\begin{aligned}
& \text { 'error points' }=\sum_{1}^{15} \\
& \text { (group rating-expert rating) }
\end{aligned}
$$

In the PROMOD condition all subjects individually worked on the task for 30 minutes. Each of them was assigned to his/her facilitator. During that time they had to write an individual draft containing a preliminary decision on how to rank the given objects. Then all given objects were judged by arguments pro and con their usefulness in order to overcome problems and threats in the relevant situation. Furthermore, all objects considered useless or dangerous were written down. Then the participants had to rank the objects. After this preliminary rank order the drafts were circulated by the facilitators. All subjects then studied the drafts of the other group members, and were requested to give written comments on each draft within 8 minutes ( $2 \times 8$ minutes). Finally, each subject was given back his/her own annotated edition. After 4 more minutes they had to come to a final individual decision (final ranking). The time schedule for the subjects working individually (synthetic groups) was identical. They also worked out a preliminary result within 30 minutes accompanied by a facilitator. After 20 more minutes they had to present a revised and final version. All participants (PROMOD groups, synthetic groups as well as control groups) worked for 50 minutes on the task at maximum (see appendix). The three female facilitators were informed about the experts' conclusions before starting the experiments in order to avoid an effect resulting from an increase of knowledge during their intervention. Each facilitator was randomly allocated the same number of groups in each cell of the $2 \times 2$ design.

\section{Results}

Data analyses reported here were carried out by means of analysis of variance ANOVA (see Tables 2 and 3). 
Table 2. Mean and, standard deviation for quality of group performance ('error points')

\begin{tabular}{lccccc}
\hline & \multicolumn{2}{c}{ Interacting groups } & & \multicolumn{2}{c}{ Nominal groups } \\
\cline { 2 - 3 } & $\begin{array}{c}\text { Means of } \\
\text { 'error points' }\end{array}$ & $S D$ & & $\begin{array}{c}\text { Means of } \\
\text { 'error points' }\end{array}$ & $S D$ \\
\hline No PROMOD technique applied & 61.93 & 9.56 & & 62.83 & 6.62 \\
PROMOD technique applied & 51.59 & 11.24 & & 58.56 & 9.36 \\
\hline
\end{tabular}

Note: Analysis made on $N=99$ groups.

Table 3. ANOVA results $(2 \times 2$ factor design without repeated measure $)$ deviation for quality of group performance ('error points')

\begin{tabular}{lrrrr}
\hline & $F$ & $d f$ & $p$ & eta $^{2}$ \\
\hline Real/nominal groups & 4.066 & 1 & .05 & .041 \\
PROMOD facilitated/not PROMOD facilitated & 14.013 & 1 & .00 & .129 \\
Real/nominal groups $\times$ PROMOD facilitated/not PROMOD facilitated & 2.407 & 1 & .12 & .025 \\
\hline
\end{tabular}

Note: Analysis made on $N=99$ groups.

Post hoc comparison (using the Duncan test) reveals that PROMOD-facilitated, interacting groups are the best in toto and significantly better than the PROMOD-facilitated, synthetic groups and groups which were not guided by this facilitation technique.

In general, the quality of performance when groups work on highly structured tasks is lower than the best individual performance and results are often similar to the level of the second best member of a 'natural' group concerning the quality of performance (Hollingshead, 1996; Littlepage et al., 1995). Therefore the final group result was also compared to the second best individual result before drafts were exchanged among group members, as a baseline of the quality improvement under PROMOD.

The results of the PROMOD facilitated groups show minus 5.15 error points in comparison with the second best individual decision and differ significantly from all other groups. As expected, the results of the real interacting groups correspond to the second best individual result (plus 0.07 error points). The statistical means of the nominal groups under the PROMOD condition differ from the second best individual group member by minus 2.15 error points, the statistical means of the nominal groups without PROMOD facilitation differ from the second best individual result by plus 0.17 error points-which of course has no meaning in terms of content as there was neither written nor oral communication among group members throughout. Dismaying but not unexpected is the fact that the results of self-guided groups hardly differ from those of synthetic groups under the condition where no facilitation technique is applied. In contrast, under the PROMOD-condition group members not only show better individual performance but also profit from the knowledge of their colleagues. This was demonstrated by comparing those results with the results of synthetic groups under the PROMOD condition.

\section{Discussion}

The theoretical development of the group facilitation technique PROMOD has been presented. The empirical study demonstrated its efficiency and effectiveness in improving group performance quality and enhancing group decisions. PROMOD stems from theoretical postulates that regard project teams as aimoriented information processors. Clarifying theoretical concepts first and then following this by verifying empirical research is a necessary precondition in order to further applied psychological research in the field of group 
facilitation techniques. This study aims to give an answer to the following question: Is a theoretical framework a potential guideline for developing an efficient social facilitation technique for project teams? The results of the experiment presented show that this question can be answered in the affirmative. We know that today's problems are so complex that we need the cooperation and interaction of experts. We also know that the performance of project groups is not as good as it could be when considering the specialized knowledge available in those groups. This expertise is not sufficiently used, thus, group results have so far been unsatisfactory. A diametrical strategy of theory testing and practical application of theory allows for the prediction of effects, and therefore enables the induction of positive effects and the prevention of negative effects on group interaction.

Looking at empirical results, it becomes clear that a lot of techniques are not very convincing, e.g., group brainstorming (Stroebe \& Diehl, 1994; Nijstad et al., 2003). What are the postulates behind those techniques which would enable the prediction of effects? Of course, there are more factors than the postulates presented here that could be regarded as principal candidates for the enhancement of group productivity. There is an increase in individual performance (Formula 3), and the latter groups additionally show an increase with regard to the quality of group performance in general (Formulas 1 and 2). Obviously, this is due to a highly structured reception of other persons' knowledge and thereby to the increased ability to adapt this knowledge to enhance the quality of their own decision process. This second step of quality improvement when taking decisions in groups-beyond a pure enhancement of individual performance quality-can be induced by the structured and controlled exchange of information implemented in the group facilitation technique PROMOD. Both steps induce an improvement of group performances.

Let's have a look at a new study showing that groups are able to perform better than the best individual of the group-without any facilitation technique (Laughlin, Bonner \& Miner, 2002). This study shows that a good group discussion result depends on the transparency of right solutions and ideas. The task involved was divided into several subtasks which were tackled by the group. The question is how to increase the demonstrability of arguments, suggestions and ideas and how to divide problem solving tasks in a practicable and appropriate way in general, so that subtasks can be tackled or solved individually. The crux of an efficient group facilitation technique is to make an appropriate structure available to the group members discussing a certain subject.

Input and output of information in groups are variables which determine group efficiency. In future the throughput of group decision processes will have to be focused on in a more suitable way. Throughput processes can be supported by facilitation techniques, which have to be developed by first formulating theoretical postulates summarizing the results of empirical research and then transforming these postulates into techniques which have to be tested, at best, on the basis of experimental studies.

\section{Note}

1. This material is based on work supported by the 'Deutsche Forschungsgemeinschaft' (Wi557/12-4).

\section{References}

Dalkey, N. C., \& Helmer, O. (1963). An experimental application of delphi method to the use of experts. Management Science, 9, 458-467.

Davis, J. H. (1992). Some compelling intuitions about group consensus decisions, theoretical and empirical research, and interpersonal aggregation phenomena: Selected examples, 1950-1990. Organizational Behavior and Human Decision Processes, 52, 3-38.

Davis, J. H. (1996). Small group research and the Steiner questions: The once and future thing. In E. H. Witte \& J. H. Davis (Eds.), Understanding group behaviour: Consensual action by small groups (Vol I, pp. 3-12). Mahwah, NJ: Erlbaum. 
Greitemeyer, T., \& Schulz-Hardt, S. (2003). Preference-consistent-evaluation of information in the hidden profile paradigm: Beyond grouplevel explanations for the dominance of shared information in group decisions. Journal of Personality and Social Psychology, 84, 322-339.

Grofman B. (1978). Judgemental competence of individuals and groups in a dichotomous choice situation: Is a majority of heads better than one? Journal of Mathematical Sociology, 6, 47-60.

Hackman, J. R. \& Morris, C. G. (1975). Group tasks, group interaction processes, and group performance effectiveness: A review and proposed integration. In I. Berkowitz (Ed.), Advances in experimental social psychology (Vol. 8, pp. 45-99). New York: Academic Press.

Hinsz, V. B., Tindale, R. S., \& Vollrath, D. A. (1997). The emerging conceptualization of groups as information processors. Psychological Bulletin, 121, 43-64.

Hoffman, R. R., Shadbolt, N. R., Burton, A. M., \& Klein, G. (1995). Eliciting knowledge from experts: A methodological analysis. Organizational Behavior and Human Decision Processes, 62, 129-158.

Hollingshead, A. B. (1996). The rank-order effect in group decision making. Organizational Behavior and Human Decision Processes, 68, 181-193.

Innami, I. (1994). The quality of group decisions, group verbal behavior and intervention. Organizational Behavior and Human Decision Processes, 60, 409-430.

Katzenstein, G. (1996). The debate on structured debate: Toward a unified theory. Organizational Behavior and Human Decision Processes, 66, 316-332.

Kerr, N. L., \& Tindale, R. S. (2004). Group performance and decision making. Annual Review of Psychology, 55, 623-655.

Lafferty, J. C., \& Pond, A. W. (1974). Desert survival situation. Plymouth, MI: Human Synergistics.

Laughlin, P. R., Bonner, B. L., \& Miner, A. G. (2002). Groups perform better than the best individuals on letter-on-numbers problems. Organizational Behavior and Human Decision Processes, 88, 605-620.

Laughlin, P. R., Zander, M. L., Knievel, E. M., \& Tan T. K. (2003). Groups perform better than the best individuals on letters-to-numbers problems: Informative equations and effective strategies. Journal of Experimental Social Psychology, 85, 684-694.
Lecher, S., \& Witte, E. H. (2002). FORMOD und PROMOD: Zwei Moderationstechniken zur Verbesserung von Entscheidungen in Gruppen [FORMOD and PROMOD: Two facilitation techniques to improve the decisions in groups]. Zeitschrift für Arbeits- und Organisationspsychologie, 47, 73-86.

Libby, R., Trotman, K. T., \& Zimmer I. (1987). Member variation, recognition of expertise, and group performance. Journal of Applied Psychology, 72, 81-87.

Littlepage, G. E., Schmidt, G. W., Whisler, E. W., \& Frost, A. G. (1995). An input process-output analysis of influence and performance in problem-solving groups. Journal of Personality and Social Psychology, 69, 877-889.

Lorge J., \& Solomon, H. (1955). Two models of group behavior in the solution of Heureka-type problems. Psychometrica, 20, 139-148.

Messé, L. A., Hertel, G., Kerr, N. L., Lount, R. B., Jr., \& Park, E. S. (2002). Knowledge of partner's ability as a moderator of group motivation gains: An exploration of the Koehler discrepancy effect. Journal of Personality and Social Psychology, $82,935-946$.

Moore, C. M. (1987). Group techniques for idea building (2nd printing). Newbury Park, CA: Sage.

Mullen, B., \& Copper, C. (1994). The relation between group cohesiveness and performance: An integration. Psychological Bulletin, 115, 210-227.

Nijstad, B. A., Stroebe, W., \& Lodewijkx, H. F. M. (2003). Production blocking and idea generation: Does blocking interfere with cognitive processes? Journal of Experimental Social Psychology, 39, 531-548.

Osborn, A. F. (1957). Applied imagination. New York: Scribner.

Rogelberg, S. G., Barnes-Farrell, J. L., \& Lowe, C. A. (1992). The stepladder technique: An alternative group structure facilitating effective group decision making. Journal of Applied Psychology, 77, 730-737.

Rogers, C. (1970). On encounter groups. New York: Harper \& Row.

Scheele, B., \& Groeben, N. (1988). Dialog-KonsensMethoden zur Rekonstruktion Subjektiver Theorien: die Heidelberger Struktur-Lege-Technik [Dialogueconsensus-methods to reconstruct subjective theories: The Heidelberger structure-laytechnique]. Tübingen: Francke.

Schweiger, D. M., Sandberg, W. R., \& Ragan, J. W. (1986). Group approaches for improving 
strategic decision making: A comparative analysis of dialectical inquiry, devil's advocacy and consensus. Academy of Management Journal, 29, 51-71.

Shiflet, S. (1979). Toward a general model of small group productivity. Psychological Bulletin, 86, 67-79.

Sorkin, R. D., Hays, C., \& West, R. (2001). Signal-detection analysis of group decision making. Psychological Review, 108, 183-203.

Steiner, I. D. (1972). Group process and productivity. New York: Academic Press.

Stroebe, W., Diehl, M. \& Abakoumkin, G. (1992). The illusion of group effectivity. Personality and Social Psychology Bulletin, 18, 643-650.

Stroebe, W., \& Diehl, M. (1994). Why groups are less effective than their members: On productivity losses in idea-generating groups. European Review of Social Psychology, 5, 271-303.

Witte, E. H., \& Davis, J. H. (Eds.) (1996a). Understanding group behavior: Vol. I. Consensual action by small groups. Mahwah, NJ: Erlbaum.

Witte, E. H., \& Davis, J. H. (Eds.) (1996b). Understanding group behaviour: Vol. II. Small group processes and interpersonal relations. Mahwah, NJ: Erlbaum.

Witte, E. H., \& Sack, P.-M. (1999). Die Entwicklung der Gruppenmoderation PROMOD zur Lösung komplexer Probleme in Projektteams [The development of the group technique PROMOD for solving complex problems in project teams]. Psychologische Beiträge, 41, 113-213.

Paper received 21 March 2005; revised version accepted 6 December 2005.

\section{Biographical note}

ERICH H. WITTE is professor of psychology and head of the Institute of Social, Economic, and Media Psychology at the University of Hamburg (Germany). He received his PhD from the University of Hamburg. His research interests include intimate relationships, group motivation, economic psychology, and empirical research on ethics.

\section{Appendix}

\section{PROMOD technique}

General introduction

- Reading of the cover story

Solving the problem individually by going through a given task structure

- Marking of information important for the problem solution

- Working out alternative strategies in order to master the situation

- Problems and risks associated with the alternative strategies

- Potentially positive results associated with the alternative strategies

- Weighting the severity of the problems

- Opportunities to eliminate problems by means of the objects to be valued

- Risks associated with the objects to be valued

- Preliminary decision in favor of one of the strategies

- Preliminary ranking of the objects

Information exchange

- Exchange of written forms among the group members

- Considering the arguments of the other group members

- Comparing the rankings

Resolving the problem individually

- Revision of one's own concept

- Final decision in favor of one strategy

- Re-ranking of the objects

Group integration

- Consensus or majority vote for the strategy

- Consensus or majority vote for the final ranking of the objects 